\title{
The Place of Human Papillomavirus Test in the Screening of Intraepithelial Lesions of Cervix in South-Kivu Province, DR Congo
}

\author{
Olivier Nyakio ${ }^{1,2,3^{*}}$, Fabrice Kibukila4,5, Bertin Kasongo6, Tchass Chasinga7, Gad Murenzi ${ }^{8}$, \\ Albert Tambwe ${ }^{3}$, Prosper Kakudji ${ }^{3}$, Prosper Kalenga ${ }^{3}$, Jean Baptiste Kakoma ${ }^{3}$ \\ ${ }^{1}$ Department of Gynecology and Obstetrics, Evangelical University in Africa (UEA), Bukavu, DR Congo \\ ${ }^{2}$ Department of Gynecology, Panzi General Reference Hospital, Bukavu, DR Congo \\ ${ }^{3}$ Department of Gynecology-Obstetrics, Faculty of Medicine, University of Lubumbashi, Lubumbashi, DR Congo \\ ${ }^{4}$ Department of Surgery, Official University of Bukavu (UOB), Bukavu, DR Congo \\ ${ }^{5}$ Department of Surgery, University of Burundi, Bujumbura, Burundi \\ ${ }^{6}$ Provincial Health Division, Bukavu, DR Congo \\ ${ }^{7}$ Department of Anatomopathology, Panzi General Reference Hospital, Bukavu, DR Congo \\ ${ }^{8}$ Rwanda Military Hospital, Kigali, Rwanda \\ Email: *oliviernyakio@yahoo.fr
}

How to cite this paper: Nyakio, O., Kibukila, F., Kasongo, B., Chasinga, T., Murenzi, G., Tambwe, A., Kakudji, P., Kalenga, P. and Kakoma, J.B. (2021) The Place of Human Papillomavirus Test in the Screening of Intraepithelial Lesions of Cervix in South-Kivu Province, DR Congo. Open Journal of Obstetrics and Gynecology, 11, 1125-1132.

https://doi.org/10.4236/ojog.2021.119106

Received: July 23, 2021

Accepted: September 5, 2021

Published: September 8, 2021

Copyright $\odot 2021$ by author(s) and Scientific Research Publishing Inc. This work is licensed under the Creative Commons Attribution International License (CC BY 4.0).

http://creativecommons.org/licenses/by/4.0/

\begin{abstract}
Introduction: Human papillomavirus (HPV) infection remains the most common cause of cervical intraepithelial neoplasia. The objective of this study is to evaluate the sensitivity and predictive value of the HPV test associated with the cervico-uterine smear in the screening of cervical intraepithelial neoplasia in our environment. Methodology: This is a descriptive cross-sectional study of 625 women who consulted in the department of gynecology for cervical cancer screening, of whom 300 received an HPV test; during the period from January the 1st to December 31st, 2018 at Panzi general reference hospital (South-Kivu, DRC). Data analysis was done using Epi Info version 7 software. Results: For all respondents $(n=625)$, the cervico-uterine smear was normal in $82.88 \%$, inflammatory in $2.4 \%$ of cases and with cellular atypia in $14.72 \%$. The HPV test was positive in 87 respondents against 213 negatives cases, i.e. a prevalence of HPV of $29 \%$ [95\% CI: $23.9 \%-34.5 \%$ ]. Among women with precancerous lesions, $27.6 \%$ had HPV infection; among those with normal smears, $29.3 \%$ of them had HPV infection; however, this difference was not statistically significant. Patients with dysplastic lesions, $31.3 \%$ had genotypes with very high carcinogenic potential; and for those with a normal Pap smear, $45.1 \%$ had genotypes with very high carcinogenic potential; however, this difference was also not statistically significant. Conclusion: The human papillomavirus test remains a very important indication
\end{abstract}


in the detection of cervical intraepithelial neoplasia, its sensitivity remaining clearly superior to that of cytology, especially for high grade lesions.

\section{Keywords}

Human Papillomavirus, Screening, Cervix, South-Kivu

\section{Introduction}

Cervical cancer is the second most Common cancer in women worldwide with approximately 500,000 new cases per year and 250,000 deaths. Approximately $85 \%$ of these cases occur in developing countries where women do not have access to routine screening, while in very high income regions, such as Europe, cervical cancer is only the seventh deadliest cancer in women, with around 50,000 new cases per year and 22,000 deaths and 175,000 are carriers (either symptomatic or not) [1].

In low-income regions, such as West Africa, the death rate is estimated at 23 per 100,000, compared to a rate of 2.1 in Western Europe, 1.9 in North America and 1.7 in Australia and New Zealand [2]. The difference in incidence between high and low income countries is mainly attributed to differential access, effective screening and precancerous or preventive treatment. Human Papillomavirus is the most common cause of cervical cancer; it can also lead to cancers of the oropharynx, vagina, vulva, penis and anus. It is estimated that 14 million Americans were newly infected with HPV in 2019 [3].

Cervical cancer, a formidable pathology, is however prevented by screening; provided, it is carried out early. Screening can be done by two methods, either a cervical smear (cytology) or an HPV-DNA test [1] [4].

The advantages of the HPV test over cytology have been widely discussed in the literature. The HPV test can identify women with a high grade of neoplasia or those likely to develop this form within six months. Its sensitivity seems to be significantly higher than that of cytology [5]. Pap smear screening programs continue to be practiced and significantly reduce the incidence of cervical cancer and its mortality, especially in countries with high population coverage [6]. However, one of the limitations of cytology-based screening is its low sensitivity detecting of dysplastic lesions in cervical cancer (intraepithelial neoplasia CIN $\geq$ 2). In addition to the need for repeated screening at short intervals, there is a high probability that false negative results will be repeated [6].

Screening of the human papillomavirus as the causative agent of cervical cancer was first proposed in 1990, before the era of vaccination, in order to improve the prevention of this formidable tumor pathology [6]. Thus, to minimize the risk of this disease, it is currently recommended to carry out a cytological examination every three years between 15 and 30 years; the HPV test is applied from the age of 30 to 65 years, and this three years after the last normal cytolog- 
ical examination [7].

Thus, with the aim of increasing awareness of cervical cancer screening, we decided to conduct this study, the objective of which is to assess the sensitivity and predictive value of the HPV test associated with uterine cervical-smear in screening for intraepithelial neoplasia of the cervix in our environment.

\section{Methodology}

\subsection{Study Type and Population}

This is a descriptive cross-sectional study carried out in women followed in gynecological consultation for cervical cancer screening during the period from January 1st to December 31st, 2018 at Panzi General Reference Hospital (South-Kivu, DRC).

Out of a total of 625 women registered and from whom a Cervico-uterine smear had been taken in compliance with all ethical considerations, 300 were able to benefit from a screening test for human papillomavirus infection whose test was found positive in 87 women.

Pregnant women, those already receiving treatment for cervical cancer, those who had not been screened for papillomavirus and those who refused to answer the questionnaire were excluded from the study.

\subsection{Variables}

The study variables were as follows:

Dependent variables:

1) HPV Infection: We tested all women in our study sample for HPV infection. We have grouped them into positive HPV and negative HPV;

2) Genotyping: the results made it possible to describe the genotypes according to their carcinogenic potential in groups of genotypes with very high carcinogenic potential $\mathrm{K}++$ (those comprising genotypes 16 and/or 18) and that of genotypes with high carcinogenic potential $\mathrm{K}+$ (other types than 16 and/or 18).

Independent variables: cytopathological results grouped into two classes: dysplastic lesions including atypical, low and high grade intraepithelial lesions (ASC-US + ASC-H + AGC + LSIL + HSIL) which are precancerous and those related to normal smear (normal + inflammatory smear which is not a precancerous lesion).

\subsection{Data Analysis}

Data analysis was done using Epi Info version 7 software. Descriptive statistics were used to describe the prevalence of HPV infection as well as the types of genotypes found in the respondents. The associations between HPV infection and the other factors studied (in terms of proportions observed in the contingency tables) were sought by using the Chi-square test (Pearson's test) and Fisher's exact test for the variables. Qualitative, the significance level being set at $\mathrm{p}<5$.

The same was true for the association between cytological results (dysplastic 
lesions) and HPV infection on the one hand and the association between genotypes with high carcinogenic potential and possible risk factors on the other hand.

Ethical considerations were taken into account, as mentioned above, after a favorable opinion from the local ethics committee and UNILU.

\section{Results}

For all the respondents (Table 1), the cervical-uterine smear was normal in $82.88 \%$ and inflammatory in $2.4 \%$ of cases, while the cytological abnormalities, which were found in $14.72 \%$ of cases, included $9.44 \%$ atypia ( $8.8 \%$ ASC-US, $0.48 \%$ ASC-H and $0.16 \%$ AGC), $4.48 \%$ low-grade lesions (LSIL) and $0.8 \%$ high-grade lesions (HSIL).

The HPV test was positive in 87 respondents against 213 negative cases, it means a prevalence of HPV of $29 \%$ [95\% CI: $23.9 \%$ - 34.5\%] (Table 2).

Among women with precancerous lesions, $27.6 \%$ had HPV infection; and among those with a normal smear, 29.3\% had HPV infection; however, this difference was not statistically significant (Table 3).

Among the women in whom dysplastic lesions were observed, $31.3 \%$ had genotypes with very high carcinogenic potential; and among those in whom the smear was normal, $45.1 \%$ had genotypes with very high carcinogenic potential; however, this difference was not statistically significant (Table 4).

\section{Discussion}

\subsection{Cytopathological Aspects}

The Pap smear is the currently recommended screening tool for precancerous

Table 1. Distribution of cytopathological aspects observed in the respondents.

\begin{tabular}{ccc}
\hline Cytopathologicalresults & Frequency & $\%$ \\
\hline Normal smear & 518 & 82.88 \\
Inflammatory & 15 & 2.4 \\
ASC-US & 55 & 8.8 \\
ASC-H & 3 & 0.48 \\
LSIL & 28 & 4.48 \\
HSIL & 5 & 0.8 \\
AGC & 1 & 0.16 \\
Total & $\mathbf{6 2 5}$ & $\mathbf{1 0 0}$ \\
\hline
\end{tabular}

Table 2. Prevalence of HPV infection among respondents.

\begin{tabular}{ccccc}
\hline HPV & Frequency & Percentage & \multicolumn{2}{c}{$95 \%$ CI } \\
\hline Positive & 87 & $29.00 \%$ & $23.90 \%$ & $34.50 \%$ \\
Negative & 213 & $71.00 \%$ & $65.50 \%$ & $76.10 \%$ \\
Total & 300 & $100.00 \%$ & & \\
\hline
\end{tabular}


Table 3. Cytological findings and HPV infection.

\begin{tabular}{cccccc}
\hline & \multicolumn{2}{c}{ HPV+ } & \multicolumn{2}{c}{ HPV- } & P \\
\cline { 2 - 6 } & $\mathbf{n}$ & $\%$ & $\mathbf{n}$ & $\%$ & \\
\hline Precancerouslesions & 16 & 27.6 & 42 & 72.4 & 0.46 \\
Normal smear & 71 & 29.3 & 171 & 70.7 & \\
\hline
\end{tabular}

Table 4. Cytological results and genotypes with high carcinogenic potential.

\begin{tabular}{ccccccc}
\hline & \multicolumn{2}{c}{ Genotypes K++ } & \multicolumn{2}{c}{ Genotypes K+ } & p \\
\cline { 2 - 7 } & $\mathrm{n}$ & $\%$ & $\mathrm{n}$ & $\%$ & & \\
\hline Dysplasticlesions & 5 & 31.3 & 11 & 68.7 & 1.0204 & 0.23 \\
Normal smear & 32 & 45.1 & 39 & 54.9 & & \\
\hline
\end{tabular}

cervical lesions. The technique developed by Papanicolau and Babès is inexpensive, simple and acceptable, painless and reproducible, non-invasive, without contraindication [8]. For more than half a century, it has been shown to be effective, since its inception, invasive cervical carcinoma has seen its frequency considerably reduced. However, the biopsy remains the gold standard, it is this which confirms the lesions after detection by cytology and orientation by colposcopy [8]. Biopsy is therefore indicated in low and high grade cytological lesions [8].

In our series, cervical uterine smear was normal in $82.88 \%$ and inflammatory in $2.4 \%$ of case, while cytological abnormalities, which were found in $14.7 \%$ of cases, included: $9.44 \%$ atypia (8.8\% ASC-US; $0.4 \%$ ASC-H and 0.16\% AGC); $4.48 \%$ low-grade lesions (LSIL) and $0.8 \%$ high-grade lesions (HSIL). Wang JJ et al. [9] in China found: normal cervical uterine smear in $71.7 \%$ of cases versus $14.8 \%$ of ASCUS; $8.7 \%$ LSIL and 2.3\% HSIL. Kasap B et al. [10] found, in their study in Turkey: a rate of $84.9 \%$ of normal cervical uterine smear; $1.55 \%$ ASC-US; 5.3\% LSIL and 4.0\% HSIL. Garbuglia AR et al. [11] had the following results in Italy: cervical uterine smear normal in $76.4 \%$ of cases; ASC-US, LSIL and HSIL in $24.4 \%$ of cases while Correa CM et al. [12] obtained a normal cervical uterine smear $63.2 \%$ of the time in Brazil. Agaba AP et al. [13] noted, for their part, in Nigeria: $31.7 \%$ of normal FCU; 39.3\% of ASC-US; $15.2 \%$ LSIL and 13.8\% HSIL. Takamatsu $\mathrm{R}$ et al. [14], in Laos, gave the following results: $90.7 \%$ normal cervical uterine smear; 5.3\% ASC-US; 0.6\% ASC-H; 2.3\% LSIL; 0.9\% HSIL and $0.07 \%$ SCC.

In view of the results of the aforementioned studies, we can affirm that cervical cytology was normal in the majority of cases in our series. This normality of the cervical uterine smear could be explained by the sensitivity of this examination which is approximately $70 \%$ to $80 \%$.

\subsection{Prevalence of HPV Infection among Respondents and Genotyping}

The present study found a rate of $29.0 \%$ (95\% CI $23.90 \%-34.50 \%$ ) of women 
with a positive HPV test, compared to $71.0 \%$ with a negative HPV test.

This prevalence is similar to that found by Mutombo AD et al. [15] in Kinshasa (28.2\% positive HPV test, 95\% CI 26.1\% - 30.3\%) and by Traoré I. M. A. et al. [16] in Burkina Faso (28\% positive HPV test). However, it is much higher than the prevalence of HPV infection found in Guyana (19.3\%) [17], in the United States (15.2\%) [18], in rural areas in Argentina (16\%) [19] and in rural India (10.44\%) [20]. However, it remains well below the prevalence found in China (54.87\%) [21], Equatorial Guinea (60\%) [22], Guinea Conakry (51.5\%) [23], Kenya (44.3\%) [24] and Nigeria (37\%) [25].

The discrepancy between the prevalences observed by the different studies is thought to be due to several factors, including the environment, the study population concerned, sexual habits as well as the sensitivity and specificity of the methods used for the detection of HPV.

Among women with precancerous lesions, 27.6\% had HPV infection; and among those with a normal smear, $29.3 \%$ had HPV infection; however, this difference was not statistically significant (Table 3 ). We can therefore say that the normal smear does not exclude infection with HPV, and therefore the risk of developing cervical cancer. Our results reiterate the idea of several studies which support that the sensitivity of the HPV test in screening for dysplastic lesions of the cervix remains significantly higher than that of cytology [5] [26].

\section{Conclusions}

Human papillomavirus test remains a very important indication in the detection of intraepithelial neoplasia of the cervix, its sensitivity remains significantly higher than that of cytology, especially for high grade lesions.

The systematic introduction of this diagnostic tool in our country in general and in all women with risk factors for cervical cancer constitutes cornerstones in the therapeutic approach of this pathology.

\section{Acknowledgements}

We present our special thanks to our Master Professor Emeritus KAKOMA Jean Baptiste for his supervision throughout this work.

\section{Dedication}

This work is dedicated to our Master, Professor KALENGA Prosper who has just left us due to illness. We keep the memory of him as an assiduous, rigorous and very intelligent Master, a true inspiration for young teachers. Dear Master, we pray for the eternal rest of your soul and promise to continue to honor your memory by the continuation of your works. From the heavens, please receive this work, which remains the fruit of your many efforts.

\section{Conflicts of Interest}

The authors declare no conflicts of interest regarding the publication of this paper. 


\section{References}

[1] Grce, M. and Davies, P. (2008) Human Papillomavirus Testing for Primary Cervical Cancer Screening. Expert Review of Molecular Diagnostics, 8, 599-605. https://doi.org/10.1586/14737159.8.5.599

[2] Effah, K., Amua, J.E., Dunyo, P., Akwada, G., Kalmoni, Y., Wormenor, C.M., et al. (2021) Raising Funds through Social Media to Subsidise Cervical Cancer Screening with HPV Testing in Rural Ghana-The Battor Experience. Journal of Health Care for the Poor and Underserved, 53, 1689-1699.

https://doi.org/10.1353/hpu.2021.0118

[3] Esagoff, A., Cohen, S.A., Chang, G., Equils, O. and Van Orman, S. (2021) Human Papillomavirus and Chinese International Students in the United States: Attitudes, Knowledge, Vaccination Trends, Healthcare Behaviors, and Sexual Activity. Human Vaccines \& Immunotherapeutics, 1-12. https://doi.org/10.1080/21645515.2021.1882283

[4] Zhu, Y., Wang, Y., Hirschhorn, J., Welsh, K.J., Zhao, Z., Davis, M.R., et al. (2017) Human Papillomavirus and Its Testing Assays, Cervical Cancer Screening, and Vaccination. In: Advances in Clinical Chemistry, Vol. 81, Elsevier Inc., Amsterdam, 135-192. https://doi.org/10.1016/bs.acc.2017.01.004

[5] Castanon, A., Landy, R. and Sasieni, P. (2013) How Much Could Primary Human Papillomavirus Testing Reduce Cervical Cancer Incidence and Morbidity? Journal of Medical Screening, 20, 99-103. https://doi.org/10.1177/0969141313492313

[6] Horn, J., Denecke, A., Luyten, A., Rothe, B., Reinecke-Lüthge, A., Mikolajczyk, R., et al. (2019) Reduction of Cervical Cancer Incidence within a Primary HPV Screening Pilot Project (WOLPHSCREEN) in Wolfsburg, Germany. British Journal of Cancer, 120, 1015-1022. https://doi.org/10.1038/s41416-019-0453-2

[7] Blanc, B. (2005) Le dépistage du cancer du col de l'utérus. Springer Verlag, Berlin, 180.

[8] Fernandez, H. (2005) Traité de gynécologie. Flammarion. 350-358.

[9] Wang, J.J., Lyu, L.P., Hu, Q.W., Wan, Z.Q., Dong, J., Pan, M., et al. (2017) A Proper Triage for Detecting Women with High-Risk Human Papillomavirus Genotypes Other than HPV16/18. Journal of Obstetrics \& Gynecology and Reproductive Biol$o g y, 219,113-118$. https://doi.org/10.1016/j.ejogrb.2017.10.021

[10] Kasap, B., Yetimalar, H., Keklik, A., Yildiz, A., Cukurova, K. and Soylu, F. (2011) Prevalence and Risk Factors for Human Papillomavirus DNA in Cervical Cytology. Journal of Obstetrics \& Gynecology and Reproductive Biology, 159, 168-171. https://doi.org/10.1016/j.ejogrb.2011.06.021

[11] Garbuglia, A.R., Piselli, P., Lapa, D., Sias, C., Del Nonno, F., Baiocchini, A., et al. (2012) Frequency and Multiplicity of Human Papillomavirus Infection in HIV-1 Positive Women in Italy. Journal of Clinical Virology, 54, 141-146. https://doi.org/10.1016/j.jcv.2012.02.013

[12] Corrêa, C.M., Teixeira, N.C.P., Araújo, A.C.L., Carvalho, N.O., Castillo, D.M., Campos, R.R., et al. (2011) Prevalence and Multiplicity of HPV in HIV Women in Minas Gerais, Brazil. Revista da Associação Médica Brasileira, 57, 418-423. http://www.ncbi.nlm.nih.gov/pubmed/21876925 https://doi.org/10.1016/S2255-4823(11)70088-1

[13] Agaba, P.A., Thacher, T.D., Ekwempu, C.C. and Idoko, J.A. (2009) Cervical Dysplasia in Nigerian Women Infected with HIV. International Journal of Gynecology \& Obstetrics, 107, 99-102. https://doi.org/10.1016/j.ijgo.2009.06.006 
[14] Takamatsu, R., Nabandith, V., Pholsena, V., Mounthisone, P., Nakasone, K., Ohtake, K., et al. (2017) Cervical Cytology and Human Papillomavirus among Asymptomatic Healthy Volunteers in Vientiane, Lao PDR. BMC Cancer, 17, 872. https://doi.org/10.1186/s12885-017-3900-6

[15] Mutombo, A.B., Benoy, I., Tozin, R. and Bogers, J. (2019) Prevalence and Distribution of Human Papillomavirus Genotypes among Women in Kinshasa, The Democratic Republic of the Congo. 1-9. https://doi.org/10.1200/JGO.19.00110

[16] Traoré, I.M.A., Zohoncon, T.M., Dembele, A., Djigma, F.W., Obiri-yeboah, D., Traore, G., et al. (2016) Molecular Characterization of High-Risk Human Papillomavirus in Women in Bobo-Dioulasso, Burkina Faso. BioMed Research International, 2016, Article ID: 7092583. https://doi.org/10.1155/2016/7092583

[17] Kightlinger, R.S., Irvin, W.P., Archer, K.J., Huang, N.W., Wilson, R.A., Doran, J.R., et al. (2010) Cervical Cancer and Human Papillomavirus in Indigenous Guyanese Women. American Journal of Obstetrics \& Gynecology, 202, 626.e1-7. https://doi.org/10.1016/j.ajog.2010.03.015

[18] Dunne, E.F., Unger, E.R., et al. (2007) Prevalence of HPV Infection among Females in the United States. Journal of the American Medical Association, 297, 813-819. https://doi.org/10.1001/jama.297.8.813

[19] Matos, E., Loria, D., Amestoy, G.M., Herrera, L., Prince, M.A., Moreno, J., et al. (2003) Prevalence of Human Papillomavirus Infection among Women in Concordia, Argentina: A Population-Based Study. Sexually Transmitted Diseases, 30, 593-599.

[20] Sowjanya, A.P., Jain, M., Poli, U.R., Padma, S., Das, M., Shah, K.V., et al. (2005) Prevalence and Distribution of High-Risk Human Papilloma Virus (HPV) Types in Invasive Squamous Cell Carcinoma of the Cervix and in Normal Women in Andhra Pradesh, India. BMC Infectious Diseases, 5, 116.

https://doi.org/10.1186/1471-2334-5-116

[21] Wang, J., Tang, D., Wang, J., Zhang, Z., Chen, Y., Wang, K., et al. (2019) Genotype Distribution and Prevalence of Human Papillomavirus among Women with Cervical Cytological Abnormalities in Xinjiang, China. Human Vaccines \& Immunotherapeutics, 15, 1889-1896.

[22] García-Espinosa, B., Nieto-Bona, M.P., Rueda, S., Silva-Snchez, L.F., Piernas-Morales, M.C., Carro-Campos, P., et al. (2009) Genotype Distribution of Cervical Human Papillomavirus DNA in Women with Cervical Lesions in Bioko, Equatorial Guinea. Diagnostic Pathology, 4, 31. https://doi.org/10.1186/1746-1596-4-31

[23] Keita, N., Clifford, G.M., Koulibaly, M., Douno, K., Kabba, I., Haba, M., et al. (2009) HPV Infection in Women with and without Cervical Cancer in Conakry, Guinea. British Journal of Cancer, 101, 202-208. https://doi.org/10.1038/sj.bjc.6605140

[24] Vuyst, H.D.E., Steyaert, S., Renterghem, L.V.A.N., Claeys, P., Muchiri, L., Path, M., et al. (2003) Distribution of Human Papillomavirus in a Family Planning Population in Nairobi, Kenya. Sexually Transmitted Diseases, 30, 137-142. https://doi.org/10.1097/00007435-200302000-00009

[25] Akarolo-anthony, S.N., Famooto, A.O., Dareng, E.O., Olaniyan, O.B., Offiong, R., Wheeler, C.M., et al. (2014) Age-Specific Prevalence of Human Papilloma Virus Infection among Nigerian Women. BMC Public Health, 14, 656. https://doi.org/10.1186/1471-2458-14-656

[26] Flanagan, M.B. (2018) Primary High-Risk Human Papillomavirus Testing for Cervical Cancer Screening in the United States: Is It Time? Archives of Pathology \& Laboratory Medicine, 142, 688-692. https://doi.org/10.5858/arpa.2018-0001-RA 